Supporting information for

\title{
Scaled-up 3D-printed reactor for precipitation of lecithin-modified hydroxyapatite nanoparticles
}

Michat Wojasińskil, , Joanna Latochal, Paulina Liszewskal, Łukasz Makowski ${ }^{l}$, Pawet Sobieszuk ${ }^{1, *}$, Tomasz Ciach ${ }^{1,2}$

${ }^{1}$ Warsaw University of Technology, Faculty of Chemical and Process Engineering, Waryńskiego 1,00-645 Warsaw, Poland

${ }^{2}$ Warsaw University of Technology, CEZAMAT, Poleczki 19, 02-822 Warsaw, Poland

\footnotetext{
${ }^{1}$ corresponding authors: michal.wojasinski@pw.edu.pl, pawel.sobieszuk@pw.edu.pl
} 


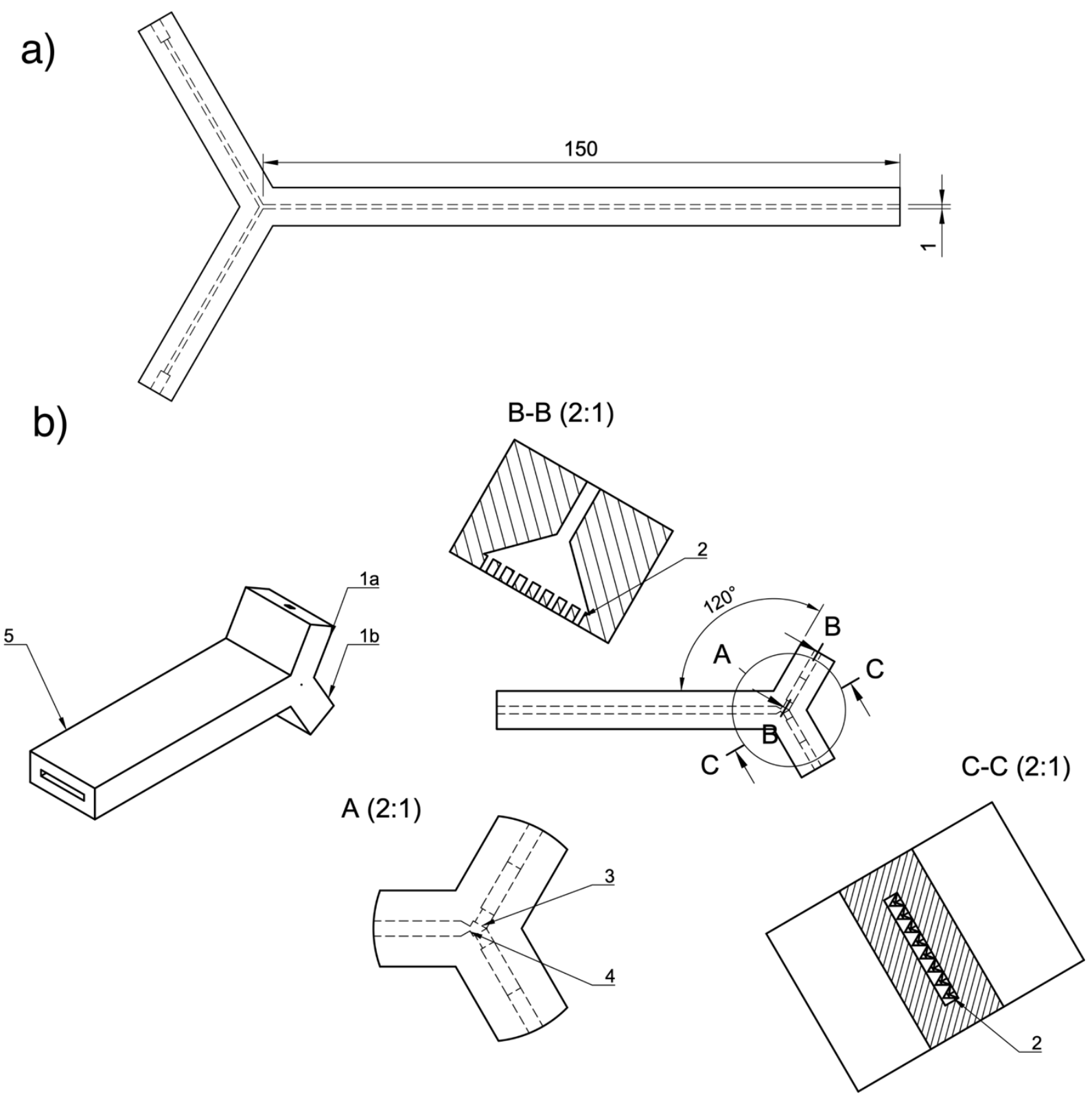

Figure S1. Detailed drawing of the study's reactors, a) Y150 reactor; b) BOX reactor. 


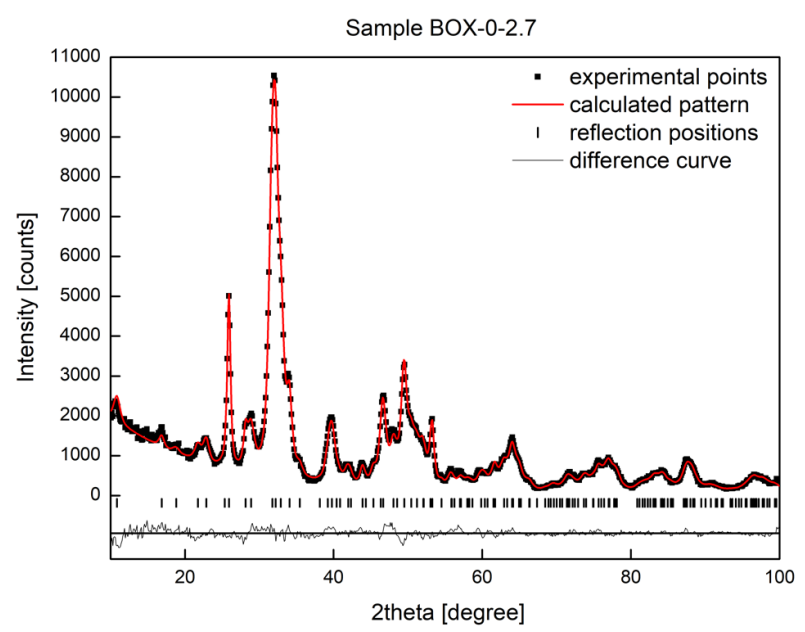

Figure S2. Results of Rietveld analysis of the XRD pattern for the BOX-0-2.7 sample of nHAp. 